\title{
Pharmaciana
}

Vol.11, No.2, July 2021, Page. 251-260

ISSN: 2088 4559; e-ISSN: 24770256

DOI: $10.12928 /$ pharmaciana.v11i2.15954

\section{Identification of Phyllanthus niruri by FTIR spectroscopy with chemometrics}

\author{
Kartini*1, Devi Hardianti $^{1}$, Mochammad Arbi Hadiyat ${ }^{2}$ \\ ${ }^{1}$ Department of Pharmaceutical Biology, Faculty of Pharmacy University of Surabaya \\ Jl. Raya Kalirungkut, Surabaya, Indonesia \\ ${ }^{2}$ Department of Industrial Engineering, Faculty of Engineering, University of Surabaya \\ Jl. Raya Kalirungkut, Surabaya, Indonesia
}

\begin{abstract}
Phyllanthus niruri (Indonesian: meniran) is a crude drug used in scientific jamu for hyperuricemia, mild hypertension, osteoarthritis, hemorrhoids, and hypercholesterolemia. This plant contains various bioactive compounds such as flavonoids, terpenes, coumarins, lignans, tannins, saponins, alkaloids, etc. Phyllanthus niruri is a wild plant growing in the tropics and sub-tropics of Asia, America, and China. This herb grows well from the lowlands to the highlands, such as bushes, terrain, yards, roadsides, gardens, and rivers. The levels of active compounds in a plant can vary depending on many factors, such as growing location, temperature, humidity, rainfall, and others. This research aimed to evaluate and differentiate $P$. niruri herbs according to their geographical location using FTIR fingerprint coupled with chemometrics, Principal Component Analysis (PCA) and Cluster Analysis (CA). The results of this study showed that 14 samples of P. niruri are classified into two groups. The first group consists of $P$. niruri powder originating from Tawangmangu, Kediri, Surabaya, Bangkalan, Gresik, Mojokerto, Kertosono, Krian, Blitar, Nganjuk, unknown 1, unknown 2, and unknown 3, whereas the second group consists of only one sample from Pasuruan. In conclusion, FTIR fingerprint analyzed with chemometrics is adequate to differentiate the powder of $P$. niruri collected from different locations. FTIR fingerprints combined with chemometrics can be further considered as a method in the quality control process of $P$. niruri.
\end{abstract}

Keywords: CA, chemometric, fingerprint, PCA, Phyllanthus niruri, quality control

\footnotetext{
*Corresponding author:

Kartini

Department of Pharmaceutical Biology, Faculty of Pharmacy, University of Surabaya

J1. Raya Kalirungkut, Surabaya, Indonesia

Email: kartini@staff.ubaya.ac.id
} 


\section{INTRODUCTION}

Jamu is a traditional Indonesian medicine with plant, animal, and/or mineral as its active ingredients. It has been used empirically for hundreds of years. Јати has been developed into standardized herbal medicine and phytopharmaca through pre-clinical and clinical tests, respectively. Another way taken by the Indonesian government to develop jamu is through the saintifikasi jamu program. This program is scientific proof of jamu through research based on health services (Siswanto, 2012). Until 2016, there were seven "scientific jamu" used for the treatment of hyperuricemia, mild hypertension, osteoarthritis, hypercholesterolemia, hemorrhoids, and dyspepsia. Those were also applied as a hepatoprotector (Triyono, 2016).

One of the crude drugs used as a component of the scientific jamu recipe is Phyllanthus niruri (Indonesian: meniran). This crude drug is used in scientific jamu for hyperuricemia, mild hypertension, osteoarthritis, hemorrhoids, and hypercholesterolemia. Moreover, this plant has been used empirically in Ayurveda and Traditional Chinese Medicine (TCM) (Bagalkotkar et al., 2006). Phyllanthus niruri contains diverse bioactive constituents including flavonoids (rutin, quercetin, quercitrin, astragalin, catechin), terpenes (limonene, p-cymene, lupeol), coumarins, lignans (phyllanthin, hypophyllanthin), tannins, saponins, alkaloids, etc. (Bagalkotkar et al., 2006; Kamruzzaman and Hoq, 2016). Phyllanthus niruri is a wild plant growing in the tropics and subtropics of Asia, America, and China (Kamruzzaman and Hoq, 2016). In these areas, P. niruri can be found from the lowlands to the highlands, such as bushes, terrain, yards, roadsides, gardens, and rivers.

Previous studies have shown that the levels of active compounds in a plant can vary according to the cultivation area, such as its temperature, humidity, rainfall, altitude, and others (Kartini et al., 2019; Pisano et al., 2015; Yudthavorasit et al., 2014). These variations cause inconsistency in the quality and efficacy of herbal products. Therefore, it is necessary to confirm the geographical origin of the $P$. niruri to maintain consistency in quality, safety, and efficacy. It can be conducted through several approaches. Determination of the concentration of one or several bioactive compounds can be carried out for this purpose. However, this method has limitations. There are various bioactive compounds contained in $P$. niruri and there may be only a slight difference in concentration at each location of growth. Hence, just determining the concentration of a few compounds is not appropriate. For this reason, an analytical technique which permits us to observe the amount of phytochemicals in a crude drug is needed. Determining the profiles of bioactive constituents through chromatography or spectroscopy is better because it will describe the chemical properties of the plant entirely (Tistaert et al., 2011).

Fourier Transform Infrared (FTIR) is a rapid and sensitive spectroscopic method to be implemented in the determination of the fingerprints of herbal medicine raw materials. FTIR spectrum contains multivariate data in the form of absorbance or transmittance in the range of wavenumber $4000-400 \mathrm{~cm}^{-1}$. Each sample will have a different spectrum profile where the transformations in the wavenumber and peak intensity of the FTIR spectrum suggest that the composition of chemical substances in the sample does change. Thus, the same plant species originated from different locations can be distinguished by their FTIR spectrum. This way, the analysis can be done even though we do not know the overall chemical compounds contained in the plant (Rohman et al., 2014; Sun et al., 2010). Distinguishing the FTIR spectra of a species with different geographical locations visually will be very difficult since the difference is only in the signal intensity. Accordingly, chemometrics is needed to distinguish them easily ( $\mathrm{Gad}$ et al., 2013). This study aimed to analyze $P$. niruri herbs based on their geographical sources using FTIR fingerprint coupled with chemometrics. In this study, the chemometrics of Principal Component Analysis (PCA) and Cluster Analysis (CA) are applied.

\section{MATERIALS AND METHOD Materials}

The plant material used was Phyllanthus niruri herb. Determination of plants was carried out by the Center for Information and Development of Traditional Medicine, University of Surabaya 
(Determination number: 1405/D.T/VIII/2019) and by B2P2TOOT Tawangmangu (determination number: YK.01.03/2/289/2020). The collection of plants was taken in June 2019 from 10 locations in East Java, 1 location in Central Java, and 3 samples with unknown sources (Table 1). Chemicals include $\mathrm{KBr}$ spectroscopy grade (Merck, Darmstadt, Germany) and demineralized water. Equipment consisted of spectrophotometer Jasco FT/IR-4200 (Japan) with DTGS (deuterated triglycine sulfate) detector, moisture content analyzer (Moisture Analyzer HB43 Mettler-Toledo GmbH, Laboratory \& Weighing Technologies, Switzerland), analytical balances (Ohaus), freeze dryer, and Ultrasonic bath (Powersonic bath AS ONE, Osaka, Japan).

Table 1. Geographical origin of Phyllanthus niruri

\begin{tabular}{llll}
\hline No. & Origin (Dristrict, province) & Height (m a.s.l) & Latitude, Longitude \\
\hline 1. & Tawangmangu, CJ & 1200 & $7^{\circ} 42^{\prime} \mathrm{S} ; 111^{\circ} 08^{\prime} \mathrm{E}$ \\
2. & Kediri, EJ & 60 & $7^{\circ} 50^{\prime} \mathrm{S} ; 112^{\circ} 01^{\prime} \mathrm{E}$ \\
3. & Pasuruan, EJ & 5 & $7^{\circ} 38^{\prime} \mathrm{S} ; 112^{\circ} 53^{\prime} \mathrm{E}$ \\
4. & Surabaya, EJ & 2 & $7^{\circ} 15^{\prime}, \mathrm{S} ; 112^{\circ} 45^{\prime}, \mathrm{E}$ \\
5. & Bangkalan, EJ & 47 & $7^{\circ} 01^{\prime} \mathrm{S} ; 112^{\circ} 45^{\prime} \mathrm{E}$ \\
6. & Gresik, EJ & 3 & $7^{\circ} 09^{\prime}, \mathrm{S} ; 112^{\circ} 39^{\prime} \mathrm{E}$ \\
7. & Mojokerto, EJ & 30 & $7^{\circ} 28^{\prime} \mathrm{S} ; 112^{\circ} 26^{\prime} \mathrm{E}$ \\
8. & Kertosono, EJ & 56 & $7^{\circ} 35^{\prime}, \mathrm{S} ; 112^{\circ} 06^{\prime} \mathrm{E}$ \\
9. & Krian, EJ & 3 & $7^{\circ} 24^{\prime} \mathrm{S} ; 112^{\circ} 35^{\prime} \mathrm{E}$ \\
10. & Blitar, EJ & 167 & $8^{\circ} 05^{\prime} \mathrm{S} ; 112^{\circ} 09^{\prime} \mathrm{E}$ \\
11. & Nganjuk, EJ & 56 & $7^{\circ} 36^{\prime} \mathrm{S} ; 111^{\circ} 53^{\prime} \mathrm{E}$ \\
12. & Unknown 1 & - & \\
13. & Unknown 2 & - & - \\
14. & Unknown 3 & - & - \\
\hline
\end{tabular}

m a.s.l: meter above sea level; CJ: Central Java; EJ: East Java

\section{Methods}

\section{Preparation of $\boldsymbol{P}$. niruri powder}

Aerial parts of $P$. niruri were used in this research (Figure 1). Plants were pulled out and then the roots and other foreign materials were removed. It was then washed with tap water, drained, and dried under indirect sunlight. P. niruri was then ground and sieved to the mesh of 45 .

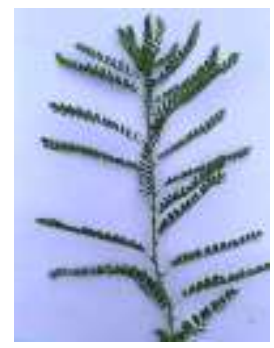

Figure 1. The aerial part of Phyllanthus niruri

\section{Extract preparation}

Five grams of powdered $P$. niruri herbs was sonicated with $60 \mathrm{~mL}$ of demineralized water using an ultrasonic bath $\left(42 \mathrm{KHz}, 50^{\circ} \mathrm{C}\right)$ for 10 minutes. Water was used as the extraction solvent to facilitate the drying process of the extract using freeze-drying. The residue was re-extracted in the same way using $40 \mathrm{ml}$ of water. Extracts were subsequently dried using a freeze dryer. 


\section{FTIR spectrum}

The FTIR spectrum was made using a spectrophotometer Jasco FT/IR-4200, with a DTGS (deuterated triglycine sulfate) detector. A total of $5 \mathrm{mg}$ of $P$. niruri powder or dried water extract was mixed with $95 \mathrm{mg}$ of $\mathrm{KBr}$, finely crushed in an agate mortar before being pressed with a manual hydraulic press to become a pellet. It was then placed in a sample holder. Spectrum was recorded in the range of $4000-400 \mathrm{~cm}^{-1}$ with a resolution of $4 \mathrm{~cm}^{-1}$ and operated with Spectra Manager Version 2 software.

\section{Principal component analysis (PCA)}

The FTIR spectra of $P$. niruri from different origins were further analyzed by applying chemometric methods, namely PCA (Principal Component Analysis) and CA (Cluster Analysis) using Minitab v.16 software (Minitab Inc., USA). PCA converts spectrophotometer FTIR data from ndimensional to principal component (PC) where there is one score describing each spectrum in a new, much lower-dimensional space in the data set. PCs are organized by their eigenvalues which quantify the number of variants sought by the PC. Then the PCs that capture the largest variation in the FTIR spectrum (the PC with the largest eigenvalue) are maintained while the PC containing only noise is discarded (the PC with the smallest eigenvalue). PCA score plots were used to objectively classify the sample from the measured traits. The sample distribution on this graph can reveal patterns that may correlate with the general characteristics of the sample. As for the loadings plot, the most varied variables will have the greatest effect on the orientation of the PCs (Yang et al., 2007).

\section{Cluster analysis (CA)}

Cluster analysis was carried out to group samples according to their chemical similarity. The samples are grouped in a high-dimensional space and thus form a dendrogram. Firstly, each sample forms a cluster, and the two closest objects are grouped. Then, the third sample joins the first two samples or the other two samples join together in a different cluster. Each stage produces one less cluster than the previous stage until all samples are finally gathered in one cluster. In this work, the mean relationship was used and the Euclidean distance was calculated (Yang et al., 2007).

\section{RESULTS AND DISCUSSION}

\section{Organoleptic feature of the sample}

Phyllanthus niruri used in this work were obtained from 11 locations. One of these samples was from Tawangmangu. $P$. niruri from this origin was used as a reference for other origins because it is used in the Saintifikasi Jamu service by B2P2TOOT Tawangmangu. There were also 3 samples from unknown origins (commercially found) which their origins were then analyzed using FTIR fingerprint data. Organoleptic features and moisture content of each $P$. niruri powder are presented in Figure 2 and Table 2, respectively.

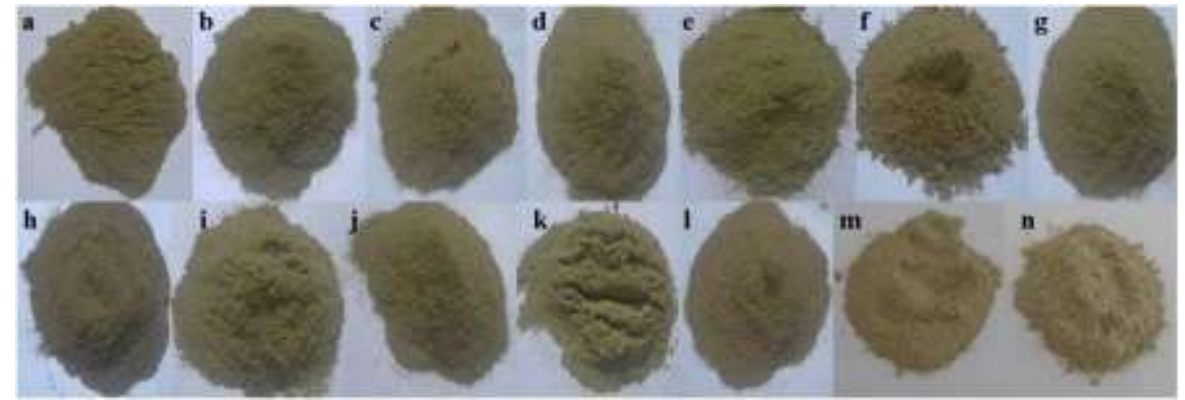

Figure 2. Powder of Phyllanthus niruri obtained from Tawangmangu (a), Kediri (b), Pasuruan (c), Surabaya (d), Bangkalan (e), Gresik (f), Mojokerto (g), Kertosono (h), Krian (i), Blitar (j), Nganjuk (k), unknown 1 (l), unknown 2 (m), and unknown 3 (n) 
Table 2. The moisture content of Phyllanthus niruri powder

\begin{tabular}{lll}
\hline No. & Origin & Moisture content $(\%)^{*}$ \\
\hline 1. & Tawangmangu & $6.65 \pm 0.16$ \\
2. & Kediri & $6.63 \pm 0.33$ \\
3. & Pasuruan & $6.62 \pm 0.13$ \\
4. & Surabaya & $6.33 \pm 0.49$ \\
5. & Bangkalan & $6.25 \pm 0.21$ \\
6. & Gresik & $6.44 \pm 0.30$ \\
7. & Mojokerto & $6.66 \pm 0.22$ \\
8. & Kertosono & $6.76 \pm 0.13$ \\
9. & Krian & $6.62 \pm 0.28$ \\
10. & Blitar & $6.65 \pm 0.15$ \\
11. & Nganjuk & $6.66 \pm 0.31$ \\
12. & Unknown 1 & $5.55 \pm 0.65$ \\
13. & Unknown 2 & $8.07 \pm 0.03$ \\
14. & Unknown 3 & $5.80 \pm 0.10$ \\
\hline
\end{tabular}

*value is mean $\pm \mathrm{SD}(\mathrm{n}=3)$

The moisture content of all of the samples was not more than $10 \%$. It indicates that the drying process that has been applied on P. niruri is sufficient. The low water and/or moisture content in plant material is important to inhibit microbial growth, the presence of fungi or insects, and deterioration following hydrolysis (WHO, 1998). Indonesian Herbal Pharmacopoeia required the LOD (Loss On Drying) of $P$. niruri is not more than $14 \%$ (RI, 2017).

\section{FTIR fingerprint of Phyllanthus niruri}

FTIR, a spectroscopic technique, is increasingly used in herbal fingerprint analysis. FTIR spectroscopy coupled with chemometrics is a fast and straightforward method and is widely used to analyze different plant species, to predict the main active constituents, and also to ensure their quality and authenticity. However, this method has drawbacks when compared to chromatography methods. There is no separation process; thus how many compounds are contained in the samples, including a crude drug as starting material of herbal medicine, cannot be predicted.

FTIR spectrum of a plant can be recorded in several ways, either by using its extract or directly using the plant powder. In this study, as a screening phase, the two methods were carried out. Phyllanthus niruri herb was extracted with water and dried under a freeze dryer. This extract and its plant powder were then crushed with $\mathrm{KBr}$ and pressed into pellets. The FTIR spectra of these two samples (Figure 3) were then compared.

Figure 3 exhibited that the spectrum of the two samples is similar. However, P. niruri powder showed a higher number of signals. Phyllanthus niruri contains various chemical constituents (Bagalkotkar et al., 2006), both polar and non-polar. Non-polar compounds such as terpenes and alkaloids are not well extracted using water; therefore, the FTIR spectrum of the water extract showed fewer bands. According to the general principle of fingerprint analysis, the constituents or sample characters are portrayed and evaluated as much as possible; hence it will be possible to take accurate conclusions. Therefore, the FTIR spectrum of all samples was carried out on P. niruri powder for the next steps. Those steps follow the previous studies (Christou et al., 2018; Man et al., 2015; Saraf et al., 2018). Technically, preparing $\mathrm{KBr}$ pellets using plant powder is more manageable, economical, and faster than extracts. 

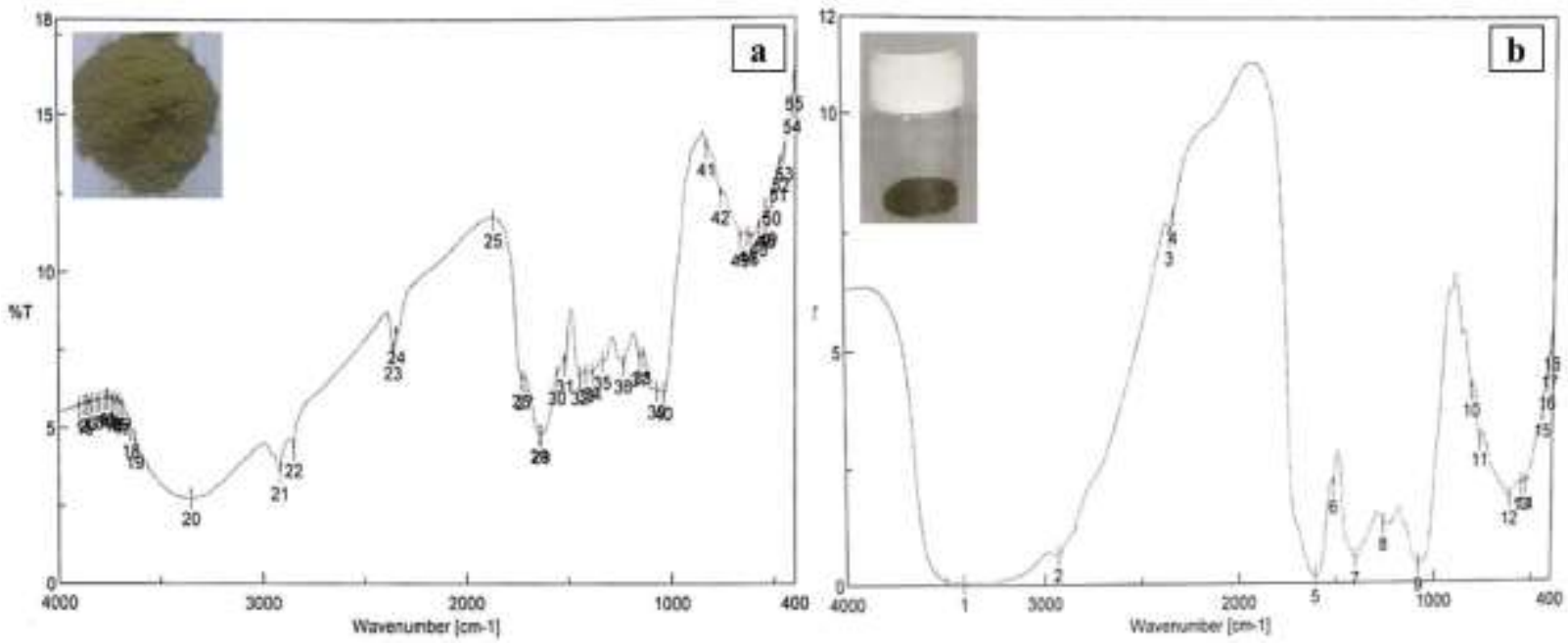

Figure 3. FTIR spectrum of Phyllanthus niruri powder (a) and its extract (b)

The FTIR profiles of $P$. niruri from various regions were very identical, with slight differences in the transmittance of each peak. It indicates that their phytochemicals are similar, only differing in concentration (Figure 4). All samples have some distinctive bands. A reasonably wide band at wavenumber $3351 \mathrm{~cm}^{-1}$ indicates the presence of strain vibrations of the $\mathrm{O}-\mathrm{H}$ group. The bands' appearance shows stretching vibrations $\mathrm{C}-\mathrm{H}$ and $\mathrm{C}=\mathrm{O}$ at $2917 \mathrm{~cm}^{-1}, 1714 \mathrm{~cm}^{-1}$, and $1644 \mathrm{~cm}^{-1}$, respectively. Based on these bands, it is predicted that $P$. niruri contains phenolic and flavonoid compounds.

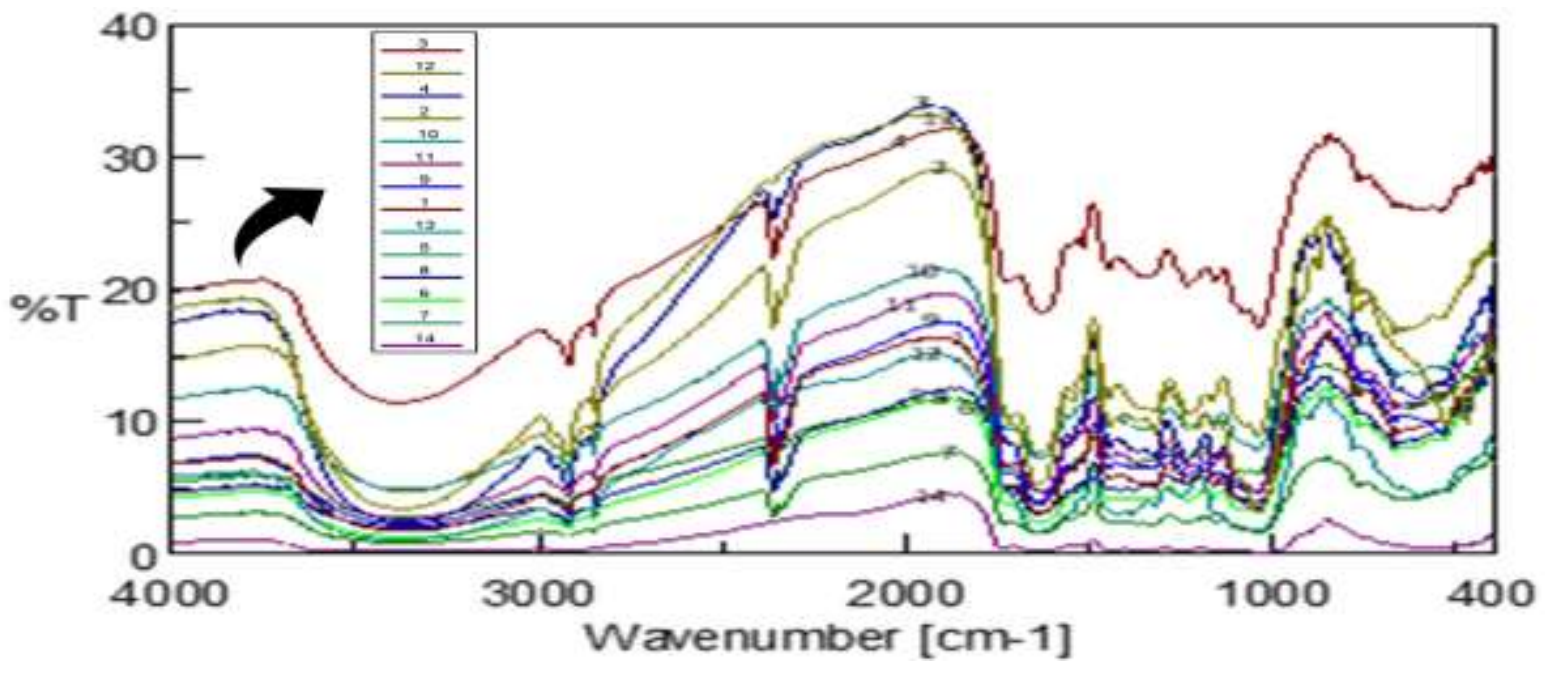

Figure 4. FTIR spectrum of Phyllanthus niruri powder from 11 origins and 3 unknown sources.

Note: Tawangmangu (1), Kediri (2), Surabaya (4), Bangkalan (5), Gresik (6), Mojokerto (7),Kertosono (8), Krian (9), Blitar (10), Nganjuk (11), unknown 1 (12), unknown 2 (13), and unknown 3 (14)

\section{FTIR fingerprint analysis by PCA}

To analyze the FTIR fingerprint of $P$. niruri, FTIR spectrum data were then tabulated. Rows reflect the origin of the samples, whereas the columns indicate the transmittance value of every peak at 
every wavenumber. The spectra at the wavenumbers of $1800-400 \mathrm{~cm}^{-1}$ were tabulated to form $14 \mathrm{x} 24$ matrix data. These multivariate data were then analyzed using PCA. The first and second PCs described $95.6 \%$ and $2.3 \%$ of the variability in the original observations respectively, and both PCs accounted for $97.9 \%$ of the total variance. Thus, the first two PCs concentrated the multidimensional information into a 2-D dataset to classify the samples. Figure 5 shows that $P$. niruri grouped into two groups, where the samples from Tawangmangu, Kediri, Surabaya, Bangkalan, Gresik, Mojokerto, Kertosono, Krian, Blitar, Nganjuk, unknown 1, unknown 2, and unknown 3 were group one, while sample from Pasuruan as group two. As a statistical tool that is driven by data, PCA works by identifying the similarity of origin's fingerprint. Although they come from different zone, if two or more origins have similar FTIR fingerprint, PCA will groups them into one group. In this research PCA excludes other variables, such as weather or geographical characteristics, it only considers FTIR fingerprint data. Figure 5 shows that different zones can have similar FTIR fingerprint, only Pasuruan origin has significant FTIR fingerprint difference, so it can not be grouped with others.

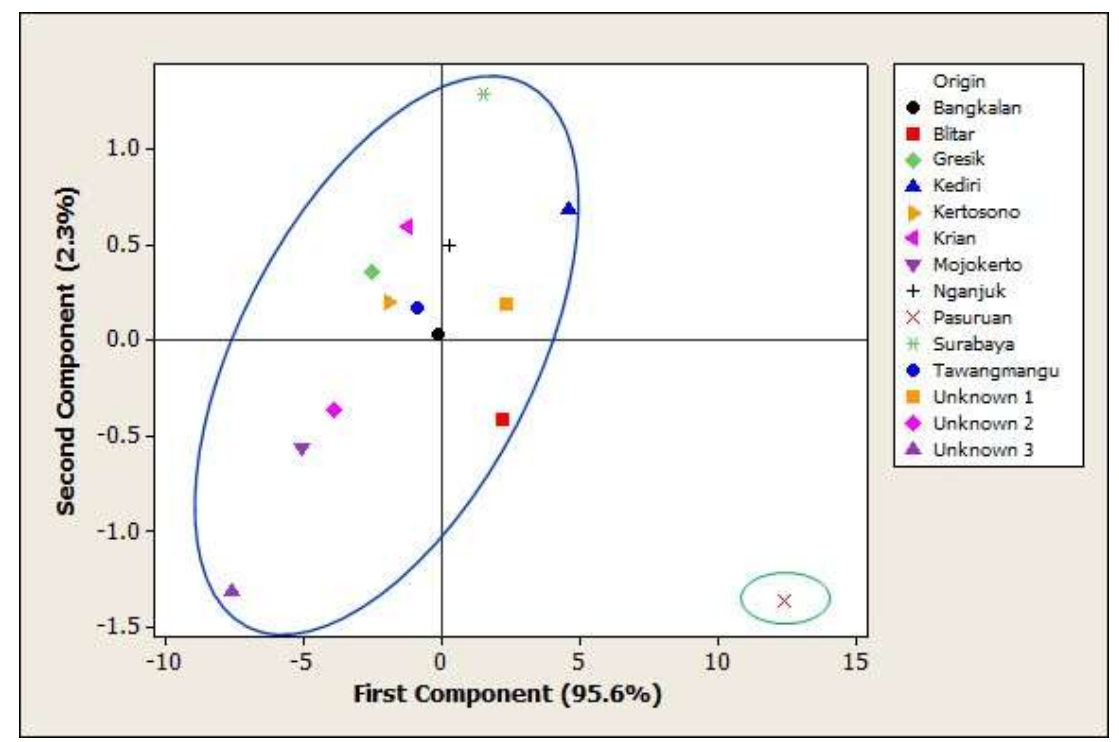

Figure 5. Principle component analysis (PCA) score plot

\section{FTIR fingerprint analysis by CA}

Although PCA can exhibit groups like multiple objects, PCA does not always do this successfully. Therefore, in this study, CA-Cluster Analysis - was created to acquire groups from the auto-scaled data set and compare those two with previous ones from PCA. As the basis for classification, two main components are taken. The clusters formed (Figure 6) indicated distinct characteristics in $P$. niruri. In this research, CA uses a single linkage with Euclidean distance to measure the similarity among origins. This analysis also found that $P$. niruri can be classified into two clusters as in PCA. The first cluster is marked in red, while the second cluster is marked in green. The first cluster consists of $P$. niruri originating from Tawangmangu (1), Kediri (2), Surabaya (4), Bangkalan (5), Gresik (6), Mojokerto (7), Kertosono (8), Krian (9), Blitar (10), Nganjuk (11), unknown 1 (12), unknown 2 (13), and unknown 3 (14). The second cluster consists of only one sample, which was from Pasuruan (3). P. niruri from Tawangmangu is a standard material for Saintifikasi Jати practice. Therefore, this research indicated that all samples except Pasuruan have a similar quality to those from Tawangmangu.

In this case, the CA result was not different from PCA. Only Pasuruan origin has a diverse group (cluster), and this result strengthens previous analysis that FTIR fingerprint data would provide 
an alternative conclusion in grouping origins. Figure 6 shows how CA steps work; the analysis is started by grouping the first two most similar origins into a cluster, continued with other high similarity ones. Formed clusters with high similarity are then also grouped into new parent clusters. This algorithm finally showed by the dendogram. Similar to this research, CA analysis with dendogram for origins grouping is indicated in the previous study (De Luca et al., 2011).

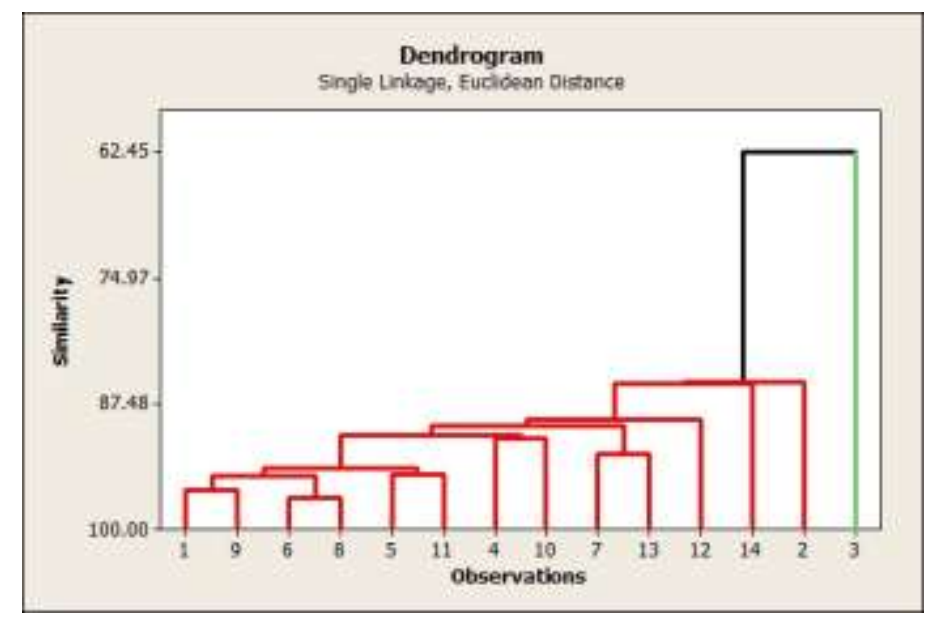

Figure 6. Dendrogram obtained from within linkage cluster analysis

Note: Tawangmangu (1), Kediri (2), Surabaya (4), Bangkalan (5), Gresik (6), Mojokerto (7),Kertosono (8), Krian (9), Blitar (10), Nganjuk (11), unknown 1 (12), unknown 2 (13), and unknown 3 (14)

\section{CONCLUSION}

Based on the FTIR fingerprint coupled with PCA and CA, Phyllanthus niruri from eleven origins in East and Central Java as well as three unknown samples can be grouped into two clusters. The first cluster consists of $P$. niruri from Tawangmangu, Kediri, Surabaya, Bangkalan, Gresik, Mojokerto, Kertosono, Krian, Blitar, Nganjuk, unknown 1, unknown 2, and unknown 3, whereas the second cluster consists of sample from Pasuruan. FTIR fingerprint analyzed with chemometrics was adequate to differentiate the powder of $P$. niruri collected from different locations. FTIR fingerprints combined with chemometrics can be further considered as a method in the quality control process of P. niruri.

\section{ACKNOWLEDGEMENT}

The authors are grateful to Indonesian Ministry of Research and Technology/National Research and Innovation Agency (Kemenristek/BRIN) for financial support of this research under PDUPT Research Scheme with the grant number 008/SP-Lit/LPPM-01/ Dikbudristek/Multi/FF/VII/2021.

\section{REFERENCES}

Bagalkotkar, G., Sagineedu, S., Saad, M., \& Stanslas, J. (2006). Phytochemicals from Phyllanthus niruri Linn. and their Pharmacological Properties: A Review. Journal of Pharmacy and Pharmacology, 58(12), 1559-1570. https://doi.org/10.1211/jpp.58.12.0001

Christou, C., Agapiou, A., \& Kokkinofta, R. (2018). Use of FTIR Spectroscopy and Chemometrics for the Classification of Carobs Origin. Journal of Advanced Research, 10, 1-8

De Luca, M., Terouzi, W., Ioele, G., Kzaiber, F., Oussama, A., Oliverio, F., . . Ragno, G. (2011). Derivative FTIR Spectroscopy for cluster analysis and classification of morocco olive oils. Food Chemistry, 124(3), 1113-1118. https://doi.org/10.1016/j.foodchem.2010.07.010 
Gad, H. A., El-Ahmady, S. H., Abou-Shoer, M. I., \& Al-Azizi, M. M. (2013). Application of chemometrics in authentication of herbal medicines: a review. Phytochemical Analysis, 24(1), 124. https://doi.org/10.1002/pca.2378

Kamruzzaman, H. M., \& Hoq, O. (2016). A review on ethnomedicinal, phytochemical and pharmacological properties of Phyllanthus niruri. Journal of Medicinal Plants Studies, 4(6), $173-180$

Kartini, K., Avanti, C., Phechkrajang, C., \& Vallisuta, O. (2019). Antioxidant activity, HPTLC Fingerprint, and discriminant analysis of plantago major leaves from diverse origins in Indonesia. Pharmacognosy Journal, 11(6Suppl), 1483-1489. http://www.phcogj.com/

Man, S., Kiong, L. S., Abâ, N. A., \& Abdullah, Z. (2015). Differentiation of the White and Purple Flower Forms of Orthosiphon Aristatus (Blume) Miq. BY 1D and 2D Correlation IR Spectroscopy. Jurnal Teknologi, 77(3), 81-86. https://doi.org/10.11113/jt.v77.6010

Pisano, P. L., Silva, M. F., \& Olivieri, A. C. (2015). Anthocyanins as markers for the classification of argentinean wines according to botanical and geographical origin. Chemometric Modeling of Liquid Chromatography-mass Spectrometry Data. Food Chemistry, 175, 174-180. https://doi.org/10.1016/j.foodchem.2014.11.124

RI, D. (2017). Farmakope Herbal Indonesia Edisi II. Jakarta: Departemen Kesehatan Republik Indonesia

Rohman, A., Riyanto, S., Sasi, A. M., \& Yusof, F. M. (2014). The Use of FTIR Spectroscopy in combination with chemometrics for the authentication of red fruit (Pandanus conoideus Lam)

Oil from Sunflower and Palm Oils. Food Bioscience, 7, 64-70. https://doi.org/10.1016/j.fbio.2014.05.007

Saraf, A., Saraf, A., \& Chaturvedi, A. (2018). Phytochemical analysis and chemical fingerprinting of seeds of abrus precatorius L. Chemical Science Transactions, 7(1), 63-70. DOI: $10.7598 / \mathrm{cst} 2018.1460$

Siswanto, S. (2012). Saintifikasi jamu sebagai upaya terobosan untuk mendapatkan bukti ilmiah tentang manfaat dan keamanan jamu. Buletin Penelitian Sistem Kesehatan, 15(2 Apr),203-211

Sun, S., Chen, J., Zhou, Q., Lu, G., \& Chan, K. (2010). Application of mid-infrared spectroscopy in the quality control of traditional chinese medicines. Planta medica, 76(17), 1987-1996. DOI: $10.1055 / \mathrm{s}-0030-1250520$

Tistaert, C., Dejaegher, B., \& Heyden, Y. V. (2011). Chromatographic separation techniques and data handling methods for herbal fingerprints: a review. Analytica Chimica Acta, 690(2), 148-161. https://doi.org/10.1016/j.aca.2011.02.023

Triyono, A. (2016). Tujuh ramuan jamu saintifik - pemanfaatan mandiri oleh masyarakat. Jakarta: Lembaga Penerbit Badan Penelitian dan Pengembangan Kesehatan

WHO. (1998). Quality control methods for medicinal plant materials

Yang, J., Chen, L. H., Zhang, Q., Lai, M. X., \& Wang, Q. (2007). Quality assessment of cortex cinnamomi by hplc chemical fingerprint, principle component analysis and cluster analysis. Journal of Separation Science, 30(9), 1276-1283. https://doi.org/10.1002/jssc.200600389

Yudthavorasit, S., Wongravee, K., \& Leepipatpiboon, N. (2014). Characteristic fingerprint based on gingerol derivative analysis for discrimination of Ginger (Zingiber officinale) According to Geographical Origin Using HPLC-DAD combined with chemometrics. Food Chemistry, 158, 101-111. https://linkinghub.elsevier.com/retrieve/pii/S0308814614002714 
